\title{
Maintaining efficient logistics and supply chain management operations during and after coronavirus (COVID-19) pandemic: learning from the past experiences
}

\author{
Ubaid Illahi $^{1}$ (iD $\cdot$ Mohammad Shafi Mir ${ }^{1}$
}

Received: 31 May 2020 / Accepted: 20 November 2020 / Published online: 19 January 2021

(c) Springer Nature B.V. 2021

\begin{abstract}
The outbreak of the novel coronavirus (COVID-19) forced the governing bodies across the world to ban all kinds of travel involving the movement of people. However, the policymakers have been working hard to mobilize the movement of essential goods and services considering its importance in containing the pandemic. It signifies how important the establishment and maintenance of logistics and supply chain management (LSCM) operations are, both during the containment and the successive periods. Motivated with the paramount importance of LSCM operations during the rapid spread of the novel coronavirus (COVID19) across the globe, this paper critically reviews the existing literature closely related to it. The main aim is to identify and enhance the understanding of the logistical characteristics that play a vital role during pandemics. The selection of the literature was done using Preferred Reporting Items for Systematic Reviews and Meta-Analysis (PRISMA) methodology. The classification of the selected literature was done using a tripartite framework. Results show that researchers have focused mostly on "Post-event" (48.24\%) management of logistical operations followed by the "Pre-event" (31.76\%) and least in the "Integrated" (20\%.) approaches. Furthermore, the analysis of the results provided useful insights that are discussed in detail. Also, twelve key areas have been identified that need due attention to improve the overall efficiency of the LSCM operations. We believe that the findings from this paper would be useful to the decision-makers and other stakeholders, as far as, maintaining efficient LSCM operations during as well after the pandemics are concerned.
\end{abstract}

Keywords Coronavirus/COVID-19 $\cdot$ Pandemic $\cdot$ Emergency control logistics $\cdot$ Emergency supply chain $\cdot$ Decision-making

Ubaid Illahi

ubaidillahi@nitsri.ac.in

1 Transportation Engineering and Planning Division, Department of Civil Engineering, National Institute of Technology Srinagar, Hazratbal, Srinagar, Jammu and Kashmir 190006, India 


\section{Introduction}

On 31 December 2019, a novel viral disease called coronavirus (COVID-19) caused by severe acute respiratory syndrome coronavirus 2 (SARS-CoV-2) was identified in the capital of Hubei province, the most populous city of Central China, Wuhan (WHO 2020a). In a couple of months, COVID-19 spread to a growing number of countries (mainly Europe and the United States) outside China. This spread was so rapid and massive that on 12 March 2020, the World Health Organization (WHO) declared it as a pandemic (WHO 2020b). As of 12 October 2020, Johns Hopkins University's dashboard (CSSE 2020) update showed that the total number of reported and confirmed cases across more than 212 countries, territories, and international conveyances (WHO 2020c) have crossed 37,481,821 taking the death toll to $1,076,818$. The increased urbanization and population densities could act as a catalyst to the spread of COVID-19. In response to these challenges in the prevailing situations, most of the countries declared nation-wide lockdowns, banning the foreign, domestic, as well as local travels. Compared to the initial phase of COVID-19, when the focus was primarily on medical aspects, the attention has now shifted towards the social, economic, and sustainability impacts (Gautam and Hens 2020).

Looking back in history, the world has witnessed several pandemics, for example, Spanish influenza in 1918 that killed nearly 50 million people across the globe (Tumpey et al. 2005) and the influenza $A(H 1 N 1)$ virus in 2010 which spread to 214 countries causing 18,114 deaths (WHO 2010). To contain such diseases, it is important to respond promptly by the deployment of manpower at a hierarchical level and ensure the smooth flow involving transportation as well as the distribution of essential commodities that include medicines, other medical supplies, groceries, etc. The efficiency of all the logistics and supply chain management (LSCM) operations especially during pandemics, therefore, has a crucial role to play (Arinaminpathy and McLean 2009; Jennings et al. 2008). The importance of maintaining efficient LSCM has also been recognized by the world's leading organizations like WHO. In the Activity Report by WHO (2012), the importance of logistical issues have been addressed in the following manner:

...to provide operational assistance in the ongoing management of logistics required for epidemic and pandemic preparedness and response and the rapid deployment of medical and laboratory supplies, transport, communications as well as the rapid deployment of outbreak response teams.

Motivated by the importance of LSCM during the prevailing COVID-19 pandemic across the globe, the research questions that were raised prior to compiling this review are as follows:

- Which areas and sub-areas of LSCM have received the least and most attention from the researchers?

- What are the characteristics of the LSCM that play a vital role during emergencies like a pandemic that would be useful to decision-makers and other stakeholders?

To explore the answers to the questions raised, the main objectives of this research are as follows:

- To identify, collect, and compile the published "LSCM" operations literature closely related to "epidemics or pandemics". 
- To classify the compiled literature based on a framework.

- To analyze the classified literature by identifying various logistical characteristics like attributes, objectives, constraints, problem formulations, and the optimization solutions thereof.

- To enhance the understanding of the LSCM operations during epidemics/pandemics by developing its robust definition and providing a way forward for decision-makers and other stakeholders.

The remaining article is organized as follows: First, the review methodology consisting of literature collection and compilation, and classification framework has been presented. This is followed by identifying and highlighting various LSCM characteristics. The distribution of identified characteristics of LSCM across the reviewed literature is presented, highlighting the main findings. Next, the major findings of this review are discussed. Finally, the conclusions with respect to the defined objectives are reported and some useful managerial insights are also provided.

\section{Review methodology}

\subsection{Literature collection and compilation}

To follow a scientific approach in finalizing the literature for this review, "Preferred Reporting Items for Systematic Reviews and Meta-Analysis" (PRISMA) proposed by Liberati et al. (2009) was adopted. The PRISMA consists of four stages. In Stage 1, the documents were searched from the databases. In this research, SCOPUS and PubMed databases were used to search the literature using "Advanced Search Options" recommended in TR-Circular E-C194 (Avni et al. 2015). It is worth mentioning that the research related to control of the epidemic/pandemic is quite vast; therefore, it was necessary to set out some boundaries in the first place. Considering this, the research focused on those areas of LSCM operations that incorporated the decision-making processes in one way or the other. In Stage-2, the titles and abstracts of the documents collected in the previous stage were screened. Further, in Stage-3 the documents found relevant in Stage-2 were checked in detail for relevance and appropriateness. Finally, in Stage-4, the final set of documents were finalized which were critically reviewed.

\subsection{Literature classification framework}

As far as the classification of the selected literature is concerned, a tripartite framework was utilized (Fig. 1). Level-1 consists of primary classification which is based on the time-frame (pre-event, post-event, and integrated). In Level-2, secondary classification is applied. This classification is based on context-specific characteristics such as bioterrorism, natural outbreaks, and disease repercussions. It is noteworthy that in some of the selected literature, although the LSCM related to the epidemic/pandemic was addressed, there was no specific mention regarding the context. That literature was grouped into the "assorted" category. Finally, in Level-3, tertiary classification is applied which is based on the methodologies and attributes of LSCM operations towards the optimization (solution) approaches. Figure 2 shows the distribution of finalized documents according to the tripartite framework. It is noteworthy that the tripartite framework was developed based on the 


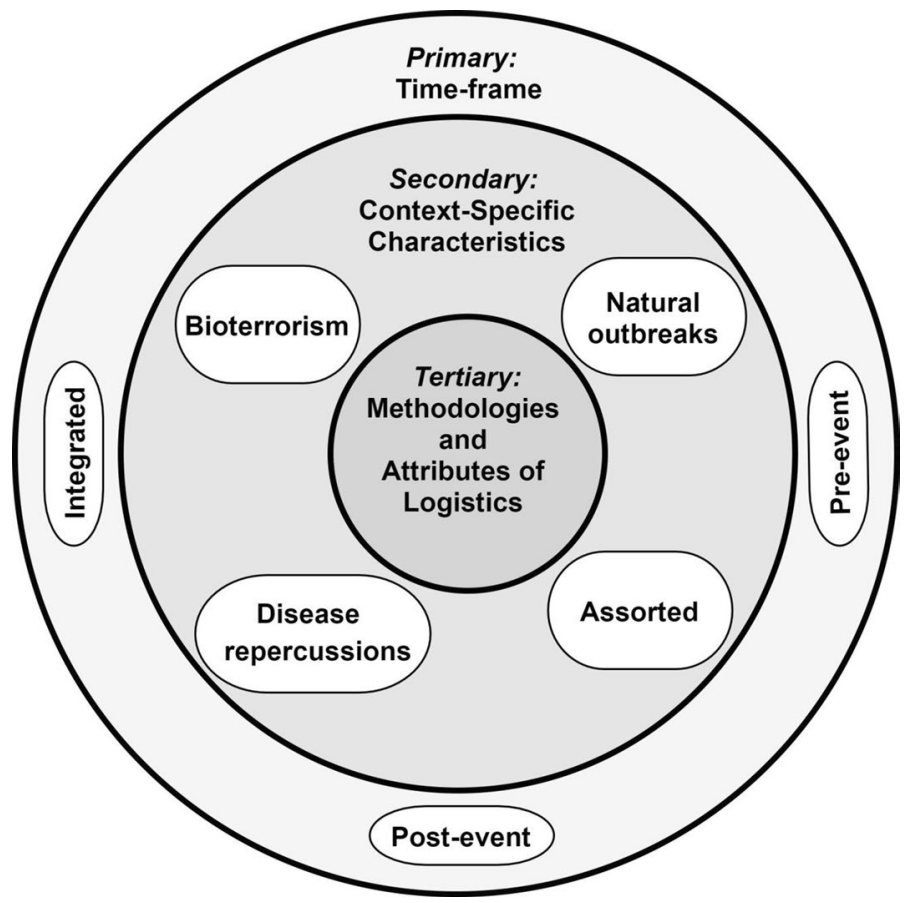

Fig. 1 Developed tripartite framework to classify the selected literature

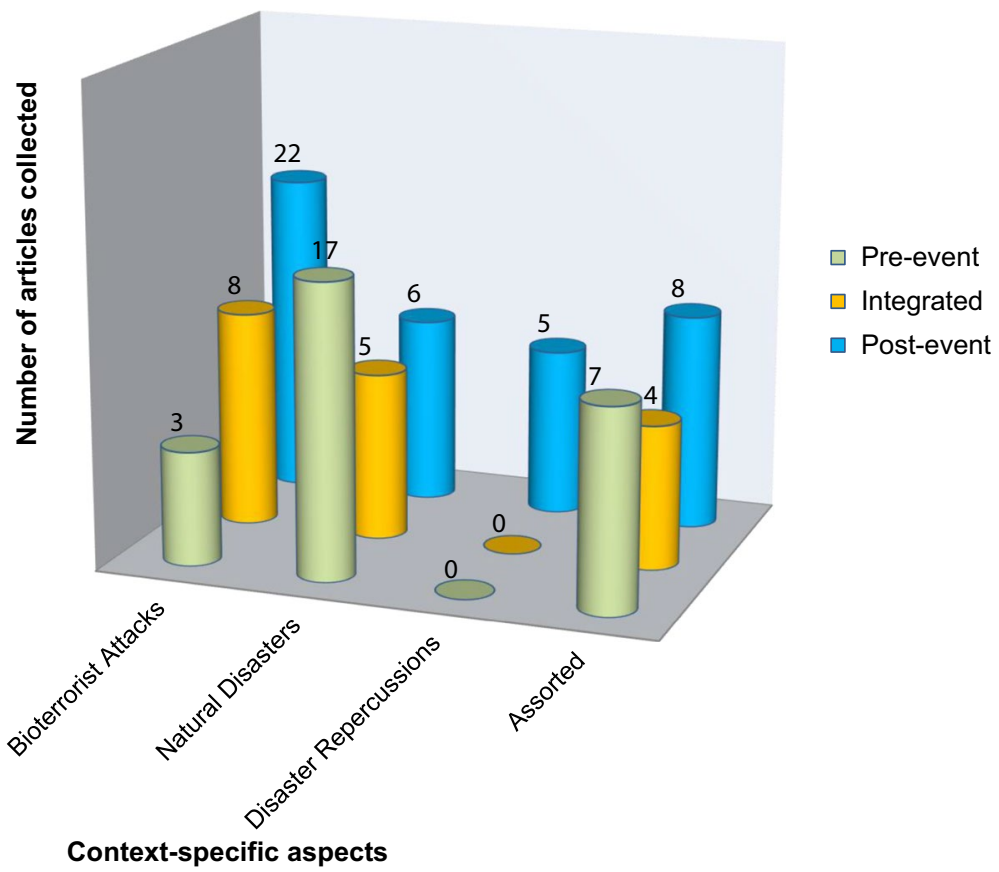

Fig. 2 Classification of the selected LSCM literature according to tripartite framework 
incorporated LSCM attributes that were identified in the selected literature. This approach helped in identifying as well as correlating the characteristics of the selected literature.

\section{LSCM operations during epidemic/pandemic}

Many decision-making issues related to LSCM arise during the containment period of an epidemic/pandemic. These issues are primarily related to facilities, their location and capacities, selection and deployment of transportation as well as distribution modes, and replenishing the stock capacities across the whole supply chain. Several research works have addressed these issues. Beeler et al. (2011) developed a discrete-event simulation model while considering various factors like crowdedness, staffing levels, and the percentage of infectious individuals entering the health care facilities. Huang et al. (2010) and Jia et al. (2007a, b) proposed several solutions related to facility locations. The solutions provided in their research were based on the models like P-median and P-centre, various heuristic, and dynamic programming approaches. Berman and Gavious (2007) formulated the problem as a game between the state and the terrorist which they solved using a combination of mathematical programming and game theory. They, in their research, considered the cost incurred in setting up the system and cost incurred in taking the required preventive measures. Murali et al. (2012) solved the problem based on the maximal covering location using loss function and locate-allocate heuristics by considering the distancesensitive demand and uncertainty in the demand. A stochastic programming model, based on a multi-objective approach, was utilized by Wang et al. (2009) to scrutinize the issues of stockpiling and dispensing activities. The solution of the model was generated through an algorithm that was based on Monte-Carlo simulations. Similarly, Ke and Zhao (2008) and E. K. Lee et al. (2009b) used dynamic programming and simulation models to solve the issues related to the distribution of essential supplies to the affected population. In these studies, various logistical constraints and issues concerned with transshipment between the dispensing points were taken into consideration, respectively. Herrmann et al. (2009) presented a delivery volume improvement technique that aids in formulating solutions considering routing and scheduling parameters. Liu and Zhao (2009) also provided a numerical simulation-based solution to the distribution of essential commodities during emergencies considering the length of route and time window as the objective functions. Liu et al. (2011) introduced a distribution model focussing on the delivery style and the delivery network of dispensing personnel, the optimization (solution) to which was obtained employing a genetic algorithm. Likewise, some researchers have worked towards solving the vehicle routing issues that arise during emergencies. For example, Shen et al. (2009) divided the vehicle routing issues into 2 stages-planning stage and operational stage. It is equally important to reduce the radius of emergency response during bioterrorist attacks and considering the replenishment policies have proved useful (Zhao and Sun 2008). Hu and Zhao (2011) studied the dynamic approaches related to the replenishment policies that arise within LSCM operations during bioterrorist attacks.

Stockpiling of essential commodities during the epidemic/pandemic is a logistical constraint (Arinaminpathy and McLean 2008) and therefore needs to be accounted for in the LSCM models. Stockpiling at central levels is less efficient during emergencies if not integrated with stockpiling at the local levels (Harrington and Hsu 2010). Cinti et al. (2005) have provided a strategic action plan for stockpiling medicines at local levels such as hospitals. Stockpiling of essential medical supplies is considered to be 
a cost-effective strategy in the case of pandemics (Dhankhar et al. 2009, 2010). For example, V. J. Lee et al. (2006a, b) and Lugnér and Postma (2009) used cost-effective approaches for stockpiling the essential medical supplies like antiviral drugs that are required during the pandemic outbreaks. A promising cost-benefit ratio can be attained if stockpiling is managed either as a therapeutic measure or as short-term preventive healthcare for exposed contacts (Balicer et al. 2005). The stockpiling decisions of an organization are not only dependent on the uncertainties in the system but also on the coordination with other partner organizations (DeLaurentis et al. 2009). Reducing the procurement costs and increasing the shortage penalty optimizes the stockpiling requirements in emergencies (Adida et al. 2011; DeLaurentis et al. 2008). Siddiqui and Edmunds (2008) proposed a decision analytical model to solve stockpiling issues related to drugs and near-patient testing for the United Kingdom. Liu (2007) developed a mathematical model to estimate the stocks required in case of an emergency like an epidemic outbreak. Likewise, Tebbens et al. (2010) considered various constraints, for example, those linked with capacity, associated risks, and filling the stockpile. They, in their research, proposed a mathematical framework that optimizes the stockpiling activities. Apart from these works, some studies have estimated the capacities of health-care centers (Radonovich et al. 2009), while others have estimated the number of personal protection kits (PPKs) required in case the pandemic outbreak occurs (Hashikura and Kizu 2009; Rebmann et al. 2011).

During the control phase of the epidemic/pandemic, logistical concerns comprise the configuration of the premises chosen to act as additional surrogate dispensing centers, patient flow management, and capacity preparation. A suite of strategies considering a reasonable level of effectiveness, time frame and resource constraints are useful in forming the robust planning framework for decision-makers (Miller et al. 2006). Contrary to this, poor control phase planning during emergencies may lead to frail decisions which, in turn, cause confusion and delayed responses (Aaby et al. 2006). This reduces the overall efficiency of the system and increases the potential number of fatalities. The simulation tools are quite beneficial in determining the optimum staff requirements for initial screening, triage operations, medical evaluation, and drug dispensing stations during the control phase (Hupert et al. 2002). Simulation tools are also useful in estimating the total time that patient stays in the system and the requirement of resources during emergencies (Patvivatsiri et al. 2007). These tools have been successfully applied to simulate other transmission diseases, for example, Porco et al. (2004) developed a continuous-time stochastic simulation model for smallpox transmission. Similarly, Whitworth (2006) utilized discrete-event simulation to strategize a response plan regarding traffic management, dispensing points, and staff scheduling intending to counter the anthrax attack. Hui (2010) developed a queuing model that was based on the time taken in the distribution of the essential supplies. To compare the emergency response during the outbreak of an epidemic/pandemic, Wein et al. (2003) proposed a mathematical modeling approach. They, in their study, considered a 2-stage queuing structure that consisted of transportation and dispensing of essential supplies and hospital care. A set of differential equations such as spatially distributed tandem queues were analyzed by Craft et al. (2005). The primary concern of their analysis was to shed light on the distribution of medical supplies and health care facilities. Giovachino et al. (2005) used various computer modeling techniques to optimize the capacity of dispensing points Kaplan et al. (2003). proposed a capacity planning tool by assessing the then-prevailing and alternate proposals for emergency responses. It has been observed that decision support systems and multi-criteria decision analysis (MCDA) have also proven successful and have been utilized by some researchers (E. K. Lee et al. 2006). For example, Richter and 
Khan (2009) utilized MCDA to evaluate the trade-offs between various dispensing strategies during an epidemic/pandemic outbreak.

On contrary to the aforementioned methods and approaches, several research works have addressed the issues of epidemic/pandemic LSCM operations from a qualitative point of view, and quantitative or integrated perspective. Here, "qualitative" refers to those studies which primarily focused on the LSCM operations concerned with the time during which quarantine or isolation programs are implemented (Barbera et al. 2001). While as, the "quantitative", refers to those studies that have developed comparatively more integrated frameworks to solve the issues of LSCM during epidemics/pandemics. For example, Y. M. Lee et al. (2009) proposed various modeling and computational tools that aid in providing robust LSCM operational planning during emergencies like a pandemic. Bravata et al. (2006) and Brandeau et al. (2008) evaluated the integrated response strategies during the bioterrorist attack using cost-benefit analysis. A dynamic compartmental model was developed by Zaric et al. (2008) to evaluate the logistical and supply chain management issues concerned with transportation and distribution of essential commodities from national to local level, stockpiling capacities, and final dispensing to local populations. Likewise, some factors affecting LSCM operations during the epidemic/pandemic were studied by Hessel and EVM-Group (2009). They, in their research, studied emergency healthcare infrastructure requirements, stockpiling aspects, and agreements between stakeholders concerning procurement and distribution of essential medical items. Apart from the factors studied in the aforementioned research works, other factors also affect the efficiency of the LSCM during the epidemics/pandemics (Collin and de Radiguès 2009). For example Adu et al. (1996), evaluated the efficiency of a cold supply chain for handling and storage factors. Similarly Moore et al. (1990), studied the logistical barriers that arise in the displaced populations and migrants. Whereas, Hadler (2005) studied the ethical issues that are linked with LSCM operations.

\subsection{Epidemic/pandemic containment objectives and the importance of coordination}

The containment of pandemic like COVID-19 encompasses mainly three major objectives. They are: (1) to reduce the rate at which vulnerable population gets infected, (2) to minimize the mortality rate of the infected population, and (3) to enhance the immunization of the population. To achieve these objectives, decision-makers and health policy-makers need to make some big decisions which include, but are not limited to, organizing quarantine programs, setting up isolation wards, launching vaccination camps, and partial/complete lockdown of a specific geographic region. For example, on 24 March 2020, the Prime Minister of India announced the nation-wide lockdown for 21 days (Economic Times 2020a) which was further extended (Economic Times 2020b) to 9 May 2020. Besides maintaining adequate sanitation facilities and law and order, the success of control measures, like these, demands equally efficient LSCM operations ensuring the smooth flow of essential commodities. This becomes an enormous challenge for authorities owing to the diversity of the entire hierarchy of stakeholders which include manufacturers, police, health departments, decision-makers, municipalities, etc. During the pandemic, it, therefore, becomes extremely important to work in coordination and come up with real-time solutions. Failing to do so, may crash the entire management system and may result in losing a huge number of precious lives (Brandeau et al. 2007). 


\subsection{Commercial supply chains vs emergency supply chains}

A supply chain is a network through which the commodities flow. It comprises of all the parties from "sourcing" and "manufacturing" to "stockpiling" and "dispensing" (Hu and Zhao 2012). To understand how a supply chain is connected among various players, Fig. 3 shows a sample supply chain that starts from the supplier and ends at the dispensing points. Reverse logistics in Fig. 3 refers to the activities that comprise disposing and treating the wastes arising from the population. Recent studies have demonstrated that adopting a multi-echelon commercial supply chain is useful. For example, Zerang et al. (2018) modeled a three-echelon supply chain considering manufacturer, third party, and retailer. Compared to commercial supply chains, emergency supply chains are no doubt more challenging because of the uncertain (Liu and Zhao 2012) and chaotic times (such as pandemic) they operate in. However, these 2 supply chains have much in common (Rottkemper et al. 2011). The nature of similarities between the two could be exploited by utilizing the knowledge and methods applied by the commercial supply chains in emergency supply chains. In other words, business models in supply chain management could be utilized in humanitarian supply chains (Blecken et al. 2010; Rottkemper et al. 2012).

\subsection{Epidemic/pandemic containment stages}

To channelize the epidemic/pandemic containment efforts, an inventory covering all the logistical operations in a number of stages, arranged sequentially are required. Broadly, WHO (2005) classifies these into four stages (Fig. 4)- preparedness, investigation, response, and evaluation.

Stage-1 (preparedness) aims at maintaining the reserve stocks of both medical as well as other essential commodities. It also aims at setting up emergency organizations and programs. For example, the National Disaster Management Authority (NDMA) was established in 2005 to spearhead and implement a holistic and integrated approach to Disaster Management in India. In recent research, Porter et al. (2020) found that setting up the emergency programs enhance the pandemic preparedness. Researchers have also developed several preparedness plans in case of an epidemic/pandemic outbreaks (Manley and Bravata 2009; Rebmann et al. 2007). Since 1999, WHO has also been regularly updating the preparedness plans for epidemic/pandemic outbreaks. As far as LSCM operations are concerned, some noteworthy points regarding such plans are listed as follows:

(1) Source identification of the essential commodities.

(2) Management of contracts and development of inventories for the procured commodities.

(3) Periodic analysis and up-gradation of medical equipment including personal protective kits (PPKs).

(4) Identification of stockpiling warehouse locations and assessment of their capacities.

(5) Planning and design of optimized transportation network systems for the distribution of essential commodities.

(6) Identification of locations for expanding the existing health-care capacities.

(7) Ensuring the adequate availability of direct as well as indirect economic resources. 


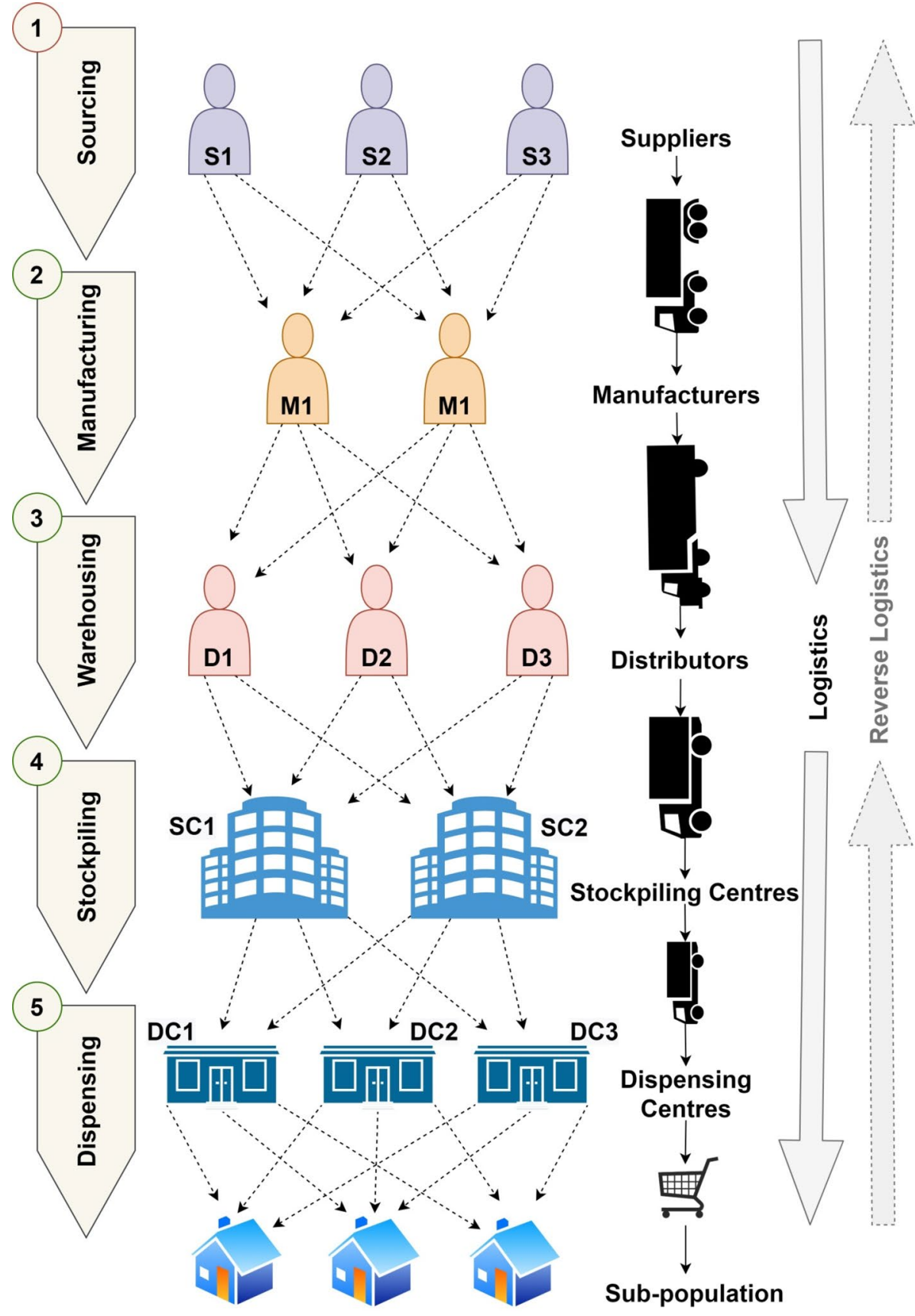

Fig. 3 The end-to-end approach of LSCM operations 


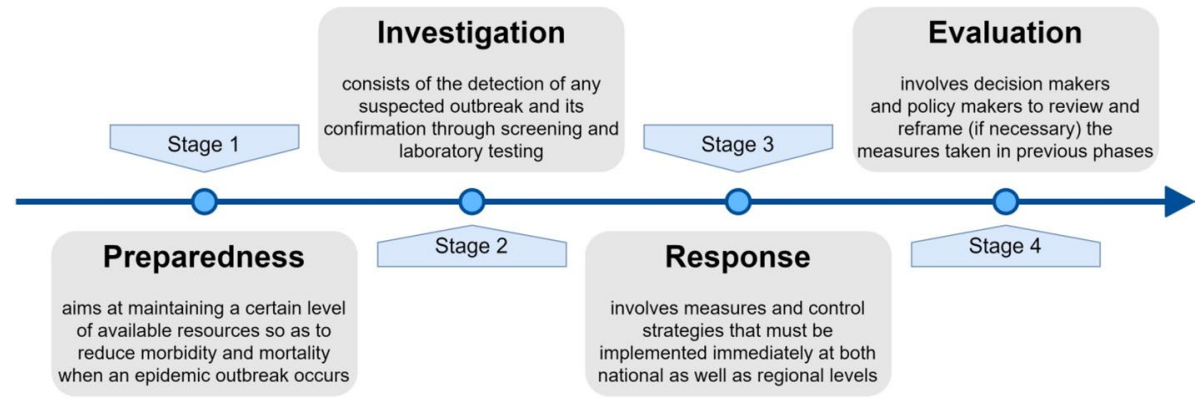

Fig. 4 Four stages of containment effort during epidemics (proposed by WHO)

In Stage-2 (investigation), systematic laboratory testing is required to be carried out to detect the infected population. It is done by establishing a well-knitted surveillance framework. Besides some leading organizations of the world, some researchers have also proposed and tested various surveillance frameworks. Dato et al. (2004) reviewed various surveillance systems that were used in the USA to detect and report the data during an outbreak. They demonstrated that the explicit understanding between the organizations involved is valuable in analyzing the complexity of the outbreaks. Lombardo et al. (2003) demonstrated the efficiency of a surveillance system that they called "Electronic Surveillance System for the Early Notification of Community-Based Epidemics (ESSENCE II)”. Likewise, Krause et al. (2007) utilized an electronic surveillance system called SurvNet to capture the impact of outbreaks in Germany. The outbreak investigation stage is difficult to handle in case of pandemics. However, it is worth mentioning that focusing on contextspecific characteristics like target population, resource availability, etc. could be useful on practical ground. The role of LSCM operations in detection and confirmation of the pandemics can be summed up as follows:

(1) Provision and supply of emergency kits including PPKs and other reporting facilities to all the frontline workers including doctors and paramedical staff among others.

(2) Organizing awareness camps for clinical workers regarding the collection of samples, their labeling, and testing and also control and treatment of the suspected and affected population.

(3) Ensuring and facilitating the operational deployment of all the essential commodities.

(4) Ensuring the efficiency of the cold supply chain which includes storing, handling, and distribution of emergency medicines/vaccines and other laboratory related materials.

(5) Ensuring the quality assurance of critical commodities.

Stage-3 (response) comes into play when the outbreak is already declared. The epidemic/pandemic curves show an exponential increase (Chinazzi et al. 2020), thus, demands immediate and rapid decisions to stop the further spread. This stage involves the execution of the plans and frameworks. As far as the role of LSCM operations during the response stage of a declared pandemic is concerned, the following points are worth mentioning:

(1) Selection of dispensing points' facilities and activation of the emergency workforce.

(2) Timetabling the vehicular routes and frequency.

(3) Transporting the essential commodities from warehouses to dispensing points. 
(4) Distribution of essential commodities from dispensing points to the local population.

(5) Reviewing and replenishing the stock of essential commodities regularly.

(6) Maintaining the cold supply chains for the medicines/vaccines.

(7) Establishing the testing centers along with the procurement of testing kits.

(8) Preparation and implementation of workforce scheduling.

(9) Utilizing the identified additional centers for quarantining and other required healthcare facilities.

(10) Following protocols for safe handling and management of the infected population and dead bodies.

(11) Maintaining law and order by employing police and other related departments.

Stage-4 (evaluation) comes into the picture after the epidemic/pandemic has been successfully contained. This stage provides useful insights into the knowledge and skills that were required for the containment (Beeler et al. 2011) and helps in upgrading and enhancing the overall management abilities of the decision-makers and health policy-makers. This could be beneficial for tackling future epidemics/pandemics, if there may be. As far as, the services of LSCM operations in Stage 4 are concerned, it is valuable in the following ways:

(1) Identifying and assessing potential bottlenecks or shortages that impeded the delivery of essential commodities to the local population.

(2) Evaluating the prioritization that would have been adhered to minimize the detrimental effects.

(3) Identifying the trends in patients needing medication adjustment or alternate care regimes.

(4) Development of performance metrics related to LSCM operations.

(5) Evaluation of teamwork problems among the stakeholders including public cooperation that was raised during the containment operations.

(6) Establishing the rehabilitation (vaccination) programs (if needed).

\section{Analysis of results}

The classification of the collected literature in this research was done based on a tripartite framework (see Fig. 1). As a result of this, a maximum (48.24\%) of the collected research works were concerned with the "Post-event" management of logistical operations followed by the "Pre-event" category which constituted a total of $31.76 \%$. Research works concerned with the "Integrated" approach (i.e. both pre-event and post-event) comprised of $20 \%$. Looking at the context-specific (secondary) classification, the maximum research works were related to "Bioterrorist Attacks" (38.82\%) followed by "Natural Disasters" (32.94\%) and "Disaster Repercussions" (5.88\%). The remaining (22.35\%) of the LSCM research works related to epidemic/pandemic have not explicitly specified the context and therefore, have been classified as the "Assorted" category. The tertiary level classification was done based on identified characteristics in the collected literature. A total of 6 broader divisions of characteristics were identified that include "logistical attributes", "objectives", "constraints", "problem formulation/methodology", "optimization (solutions)", and "nature of the study". Each of these is further categorized into sub-division characteristics. The distributions of the sub-division characteristics across the broader characteristics are shown in Figs. 5 a-f. 

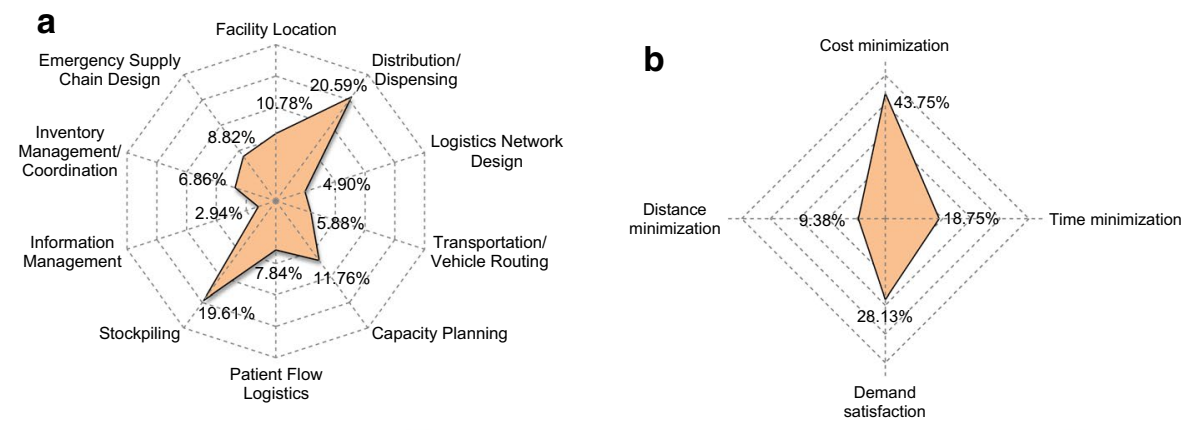

口Logistical attributes
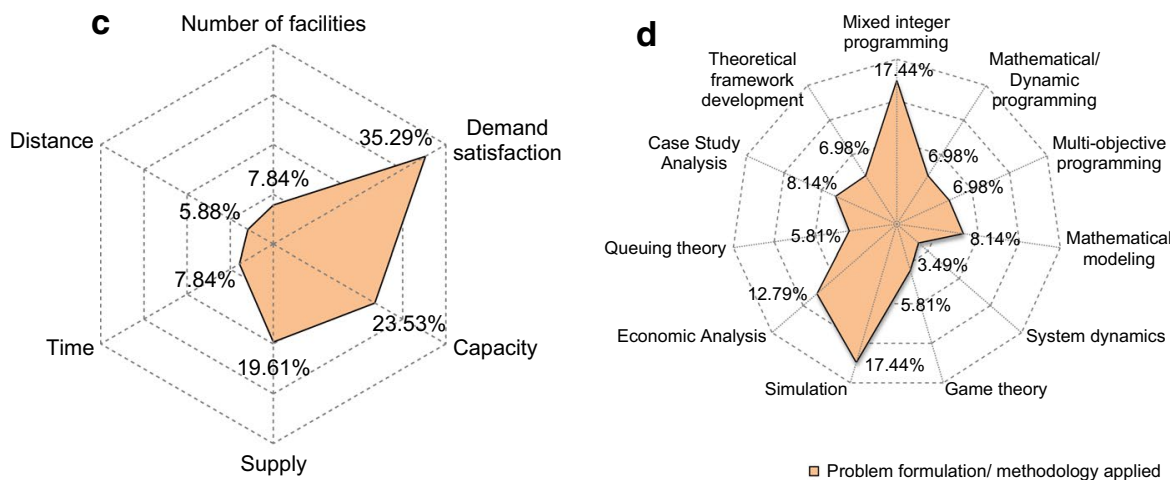

$\square$ Constraints
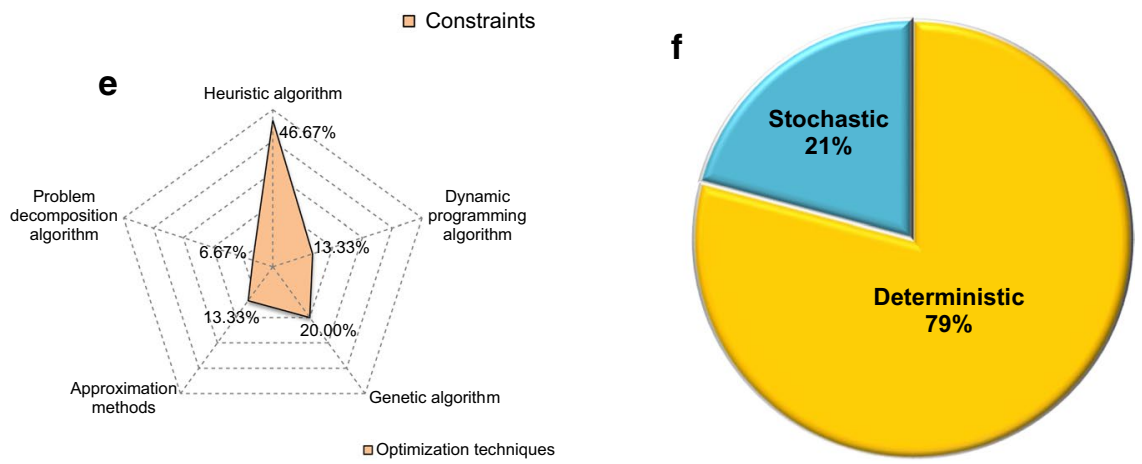

Fig. 5 Distribution of various characteristics across the collected LSCM literature related to epidemics/pandemics. a Distribution of logistical attributes across the reviewed literature. b Distribution of objectives of the reviewed literature. $\mathbf{c}$ Distribution of constraints across the reviewed literature. d Distribution of problem formulation/methodology applied across the reviewed literature. e Distribution of optimization (solutions) methods adopted across the reviewed literature. f Distribution of nature of study undertaken across the reviewed literature

Ten logistical attributes were identified in the reviewed literature (see Fig. 5a). Analysis of the literature showed that, on one hand, major research focus has been on attributes such as "distribution/dispensing" (20.59\%) and "stockpiling" (19.61\%) of the 
essential commodities during emergencies. On the other hand, "information management" (2.94\%), "logistics network design" (4.90\%), and "vehicle routing” (5.88\%) have comparatively, received the least attention. As far as the primary objectives of the reviewed LSCM literature are concerned, four objectives were identified (see Fig. 5b). Among the identified objectives, "cost minimization" (43.75\%) received the maximum attention from the researchers followed by "demand satisfaction" (28.13\%) and "time minimization" (18.75\%). Research with "distance minimization" (9.38\%) as the objective was found in the least number of reviewed literature. The analysis of the reviewed literature also shed light on various constraints applied. A total of 6 constraints were identified (see Fig. 5c) in which "demand satisfaction" (35.29\%), "capacity" (23.53\%), and "supply" (19.61\%) were found to be applied by most of the researchers. The "distance" $(5.88 \%)$ as a constraint was applied in the least number of reviewed literature.

In the analysis of the reviewed LSCM literature, it was found that a variety of methodological approaches have been used. As many as eleven such methodologies were identified (see Fig. 5d). Among these, "mixed integer programming" and "simulation tools" that accounted for $17.44 \%$ each were utilized in most of the research, while as "queueing theory" (5.81\%), "game theory" (5.81\%), and "system dynamics" (3.49\%) approaches were utilized in the least. The distribution of the identified optimization techniques in the reviewed literature is shown in Fig. 5e . Among the five identified optimization techniques, "heuristic algorithms" (46.67\%) were utilized by most of the researchers followed by "genetic algorithm" (20\%). Contrary to this, "problem decomposition algorithm" (6.67\%) was utilized by the least. Finally, two broader divisions signifying the nature of the LSCM reviewed literature were identified (see Fig.5f). It was found that most of the research is based on "deterministic" (79\%) approach when compared to "stochastic" approach (21\%).

\section{Discussion}

Reviewing and analyzing the collected LSCM literature related to epidemics/pandemics, some useful insights are derived and reported here. Several logistical characteristics were identified which shed light on various attributes, methods, and methodologies adopted by the researchers. Most of the research was found to be related to bioterrorist attacks and natural disasters. The possible reason for most of the research focused on bioterrorist attacks could be the anthrax attack in the USA that took place in the year 2001. Nevertheless, during a declared epidemic/pandemic most of the organizations come to halt but LSCM operations need to be more active than during normal times. Transportation and distribution of essential commodities from sourcing to end-users is the lifeblood during such times of crisis. The spread of epidemic as disaster repercussions remains a controversial issue and is possibly the reason for the lack of research in this area.

Analyzing the logistical attributes, it is observed that many assumptions for the sake of simplicity have been used. It is important that these assumptions are close to the realworld (practical) issues rather than to the hypothetical (ideal) conditions. For modeling the LSCM network system during the epidemic/pandemic, most of the researchers (in their methodologies), as observed, have utilized differential equations. Rates of infection and disease transmission are assumed to be constant, which of course is not true in epidemic/ pandemic situations and therefore, should be avoided. The LSCM models designed for controlling the disease outbreaks and determining the optimal amount and location of resources should take into account its spatial spread dynamics as well (Büyüktahtakın et al. 
2018). Moreover, compared to other essential commodities, it is important to follow different protocols as far as the transportation and distribution of medical supplies are concerned. The negligence in these approaches leads to chaotic issues in the fleet management of the LSCM, reducing the overall efficiency of the system.

The nature of the disease, i.e., whether the disease is contagious (say COVID-19) or not (say anthrax) and to what extent, has a direct link with the LSCM configuration. The frameworks handling the two issues need to be different. For example, the former requires much more quick responses than the latter. The time frames in which the essential commodities need to be transported and delivered may also vary (Lee 2008). Moreover, the facilities, equipment, and capacities required may not be the same. During COVID-19, for example, it is vital that the medical staff is provided with personal protection kits (PPKs) of the highest quality. This would not be the case of other non-contagious outbreaks. Hupert et al. (2004) categorize the mass prophylaxis due to the outbreak of epidemic/pandemic into the following 2 categories: (1) push approach, and (2) pull approach. In the "push" approach, the treatment is to be delivered at doorsteps or local facilities while as, in the "pull" approach, the infected population must be treated in hospitals. Therefore, tailoring the frameworks considering the nature of the outbreaks is essential. Moreover, to deal with mass prophylaxis, models based on multi-objective location-allocation problems integrating both, strategic as well as operational components are highly recommended (Pouraliakbarimamaghani et al. 2017).

The decisions regarding the sourcing and distribution of essential commodities always have a cost factor associated with it. Thus, cost minimization is no doubt vital towards efficient LSCM during epidemics/pandemics but it is equally important to incorporate and optimize other elements as well. For example, Zhao and Han (2010) proposed an LSCM design framework with the main aim to reduce both the overall costs incurred as well as response times. Xu et al. (2009) studied the relationship between two LSCM networksepidemic diffusion and emergency rescue. Zhu and Cao (2010) developed an LSCM network model based on the following three stages: (1) the emergency behaviors of relief suppliers, (2) the emergency behaviors of distribution centers, and (3) the demand equilibrium conditions of affected areas. Similarly, the elements like picking, packing, in-door handling, maintenance, and transshipment precautions call for equal importance. Also, the replenishment and trade-off policies should be given due consideration as the stock capacities are limited and could be a major issue in case the epidemic/pandemic extends for a longer period. Other elements like proper timetabling and scheduling of the workforce, considering fatigue and health implications should also be respected and, therefore, necessitates attention.

The management and broadcasting of information are useful in retarding the progression of the disease outbreaks. Information management during epidemics/pandemics acts as a driving force for efficient LSCM operations (Conn et al. 2008). Updating the whole hierarchical workforce regularly regarding the planning modifications which include transportation of essential commodities, the requirement of the additional workforce, and deployment tactics play a crucial role in the smooth functioning of the LSCM operations. Some proven and well-established business supply chain models could be calibrated to suit the emergency needs during epidemic/pandemics. Some latest technologies like radio frequency identification (RFID) and RealOpt (E. K. Lee et al. 2009a) could also be utilized for improving the efficiency of LSCM.

To tackle and successfully manage the complexity of public health and economic systems during the outbreak of epidemic/pandemic, a substantial effort, and a multidisciplinary approach is required (Silal 2020). An integrated approach that incorporates spatial and social 
heterogeneities, epidemic/pandemic dynamics, budget allocation as well as the capability to adapt government interventions are useful in improving the efficiency of LSCM operations during pandemics (Liu et al. 2020). The coordination among all the stakeholders actively involved in the containment of the epidemic/pandemic is the key to success. Containment strategies involve the public as well as private organizations, pharmaceutical as well as nonpharmaceutical personnel, law enforcement as well as transportation and LSCM departments, researchers as well as practitioners, among many others. These need to come under one roof and work in coordination (Manley and Bravata 2009). It is further validated by the fact that decision in one sector affects the execution part in the other and vice-versa. The coordination of the public is equally important for the success of containment efforts. It has been observed that lack of coordination is seen more in situations like epidemic/pandemic outbreak, owing to uncertainty, and this results in poor execution works. In other words, it can be interpreted that without proper coordination even if robust frameworks are developed, they do not benefit at the ground level.

It is observed that most of the logistical studies related to epidemic/pandemic control have developed prescriptive or descriptive models using a deterministic approach; however, including stochastic features would be more useful. An example that supports this claim is that of the time parameter. Despite the time parameter being very critical in addressing issues during epidemics/pandemics, it is often assumed to be constant in the deterministic approach. This raises some serious questions regarding the robustness of the models developed, especially concerning the logistical operations during disease outbreaks. Thus, the incorporation of stochastic parameters cannot be overlooked. Nevertheless, breaking down tasks into smaller ones would also be useful in maintaining efficient LSCM operations during pandemic like COVID-19.

The number of confirmed cases and deaths alone during the epidemic/pandemic does not show a complete and clear picture. Similarly, in LSCM operations during the epidemic/pandemic, the simple statistical parameters could be misleading. It is, therefore, highly recommended to develop various performance metrics or indicators and possibly integrate those to develop composite indices (see, for example, Illahi and Mir 2020a, b). Multi-Criteria Decision Making (MCDM) methods are quite useful in assessing such indicators representing a complex problem (Yıldızbaşı et al. 2020). The developed indices could be useful in the evaluation and assessment of the logistical operations; thus, aiding in taking further decisions.

Finally, during the epidemic/pandemic outbreaks, proper sanitation and maintenance of hygiene within the societies are even more important. This is because the risk of spreading some other diseases increase many folds due to an inefficient reverse logistics network which, in turn, may add to the public health burden. Reverse logistics encompasses all those activities that involve the collection and disposal of both medical as well as household wastes. Designing robust reverse logistics models is important especially during epidemic/pandemic periods. As an example, in a recent study, Kargar et al. (2020) presented a mathematical model based on the following three objectives: (1) minimizing the total cost, (2) reducing the risk levels, and (3) minimizing the amount of uncollected waste. The implementation of the developed reverse logistics models is equally important.

\section{Conclusion and managerial implications}

The pandemic outbreak poses a high risk for the population at local, national as well as global levels. Since the other activities might be forced to a halt during the containment stages of pandemics like COVID-19, LSCM has a vital role to play. The efficiency of 
LSCM operations improves the transportation and distribution of essential commodities including the medical supplies during the containment period. Similarly, after the containment period, the major role of LSCM is to reach out to a mass population so that people get vaccinated. Considering the importance of LSCM to decision-makers and other stakeholders, this paper reviewed the literature using PRISMA. Several gaps were highlighted and discussed. It was found that the literature is mostly focused on post-event management; however, an integrated approach is given little attention. Moreover, the evidence from this review suggests that the modeling approaches and frameworks have poor correlation with the practical-case scenarios that make their applicability questionable and limited. Finally, in line with the research objectives and based on the analysis of the collected literature, a set of twelve managerial implications are recommended. We believe these recommendations will prove useful to decision-makers and other stakeholders in tackling the LSCM issues during pandemic emergencies like COVID-19 and alike situations that may arise in the future. They are as follows:

(1) Interdisciplinary approach: there is a strong need for both epidemiologists and transport planners to join hands and develop tailor-made epidemic/pandemic logistical and supply chain frameworks and models. The models based on multi-echelon, multiperiod, multi-vehicle, etc. could prove beneficial in this regard.

(2) Holism and integrity: to contain the outbreak of a pandemic, a holistic and integrated approach encompassing the logistical arrangements from sourcing of essential commodities to distribution among the populations plays a vital role.

(3) Replenishment frameworks: stocks have a definite capacity which should be respected in designing the framework for logistical operations. Framing the LSCM network system without considering the replenishment parameters makes it weak, and therefore, these parameters are essential to be incorporated.

(4) Synchronized tactics: the logistical tactics must be well synchronized having the consensus of most (if not all) of the decision-makers and other relevant stakeholders.

(5) Stochastic parameters: the developed LSCM models should include the stochastic parameters like the capacity of the warehouses, the time required for transportation and distribution of essential commodities, quarantine times, etc.

(6) Practical constraints: planning LSCM operations should necessarily take into account practical constraints like availability of frontline workers, their timetabling and scheduling, etc. This will, in turn, optimize the health-care handling facilities.

(7) Developing indicators: continuous evaluation and assessment of LSCM operations are necessary as it keeps a track of the implemented plans. Developing indicators or indices could simplify things and aid in otherwise complicated tasks.

(8) Modeling mass gatherings: if the mass gatherings cannot be avoided completely, robust models must be developed beforehand.

(9) Information and broadcasting: it is mandatory that all the stakeholders from decisionmakers to ground workers including the public are well informed and regularly motivated and updated about the logistical operations. This often has been either neglected or given less weightage leading to chaos.

(10) Hierarchical coordination: coordination across the whole workforce is the key to provide efficient LSCM operations during the epidemic/pandemic. Therefore, it is necessary to identify the role of all the participants across the hierarchical levels followed by working in coordination during the response times as well as during the post-containment periods. 
(11) Reverse logistics: sanitation issues being the primary cause of concern during epidemics/pandemics, the wastes (both medical and household) need to be treated properly and well in time. It, therefore, also calls for designing efficient reverse logistics.

(12) Realistic assumptions: for researchers, it is proposed that assumptions made in developing logistical models should be more realistic. Most of the researchers, for example, have optimized the cost while keeping the time constant. However, the latter is a critical parameter as far as the pandemic is concerned.

Acknowledgments The authors would first like to thank the anonymous reviewers for providing valuable comments and suggestions which improved the overall quality of this manuscript. The authors would also like to acknowledge and thank all the frontline soldiers across the globe including doctors, medical staff, public health policymakers, municipality staff, police personnel, administrative officials, people associated with ensuring essential supplies, and all the others who deserve mention for working tirelessly to save precious lives in difficult times of COVID-19 pandemic.

\section{Compliance with ethical standards}

Conflict of interest The authors declare that they have no competing interest.

\section{References}

Aaby, K., Herrmann, J. W., Jordan, C. S., Treadwell, M., \& Wood, K. (2006). Montgomery county's public health service uses operations research to plan emergency mass dispensing and vaccination clinics. Interfaces, 36(6), 569-579. https://doi.org/10.1287/inte.1060.0229.

Adida, E., DeLaurentis, P.-C.C., \& Lawley, M. A. (2011). Hospital stockpiling for disaster planning. IIE Transactions (Institute of Industrial Engineers), 43(5), 348-362. https://doi.org/10.1080/07408 17X.2010.540639.

Adu, F. D., Adedeji, A. A., Esan, J. S., \& Odusanya, O. G. (1996). Live viral vaccine potency: An index for assessing the cold chain system. Public Health, 110(6), 325-330. https://doi.org/10.1016/s0033 $-3506(96) 80003-5$.

Arinaminpathy, N., \& McLean, A. R. (2008). Antiviral treatment for the control of pandemic influenza: Some logistical constraints. Journal of the Royal Society Interface, 5(22), 545-553. https://doi. org/10.1098/rsif.2007.1152.

Arinaminpathy, N., \& McLean, A. R. (2009). Logistics of control for an influenza pandemic. Epidemics, 1(2), 83-88. https://doi.org/10.1016/j.epidem.2009.04.001.

Avni, A., Burley, P, Casey, P, Cherney, J, Christiansen, L, Daly, J. S., et al. (2015). Literature searches and literature reviews for transportation research projects: How to search, where to search, and how to put it all together: Current practices. Transportation research circular. Washington, DC: Transportation Research Board (TRB).

Balicer, R. D., Huerta, M., Davidovitch, N., \& Grotto, I. (2005). Cost-benefit of stockpiling drugs for influenza pandemic. Emerging Infectious Diseases, 11(8), 1280-1282. https://doi.org/10.3201/eid11 08.041156 .

Barbera, J., Macintyre, A., Gostin, L., Inglesby, T., O’Toole, T., DeAtley, C., et al. (2001). Large-scale quarantine following biological terrorism in the United States. Journal of American Medical Association, 286(21), 2711-2717. https://doi.org/10.1001/jama.286.21.2711.

Beeler, M. F., Aleman, D. M., \& Carter, M. W. (2011). Estimation and management of pandemic influenza transmission risk at mass immunization clinics. In: Proceedings of the winter simulation conference (pp. 1117-1124). IEEE.

Berman, O., \& Gavious, A. (2007). Location of terror response facilities: A game between state and terrorist. European Journal of Operational Research, 177(2), 1113-1133. https://doi.org/10.1016/j. ejor.2005.12.022.

Blecken, A., Danne, C., Dangelmaier, W., Rottkemper, B., \& Hellingrath, B. (2010). Optimal stock relocation under uncertainty in post-disaster humanitarian operations. In: Proceedings of the 43rd Hawaii 
international conference on system sciences (pp. 1-10). IEEE. https://doi.org/10.1109/HICSS .2010 .296 .

Brandeau, M. L., Hutton, D. W., Owens, D. K., \& Bravata, D. M. (2007). Planning the bioterrorism response supply chain: Learn and live. American Journal of Disaster Medicine, 2(5), 231-247.

Brandeau, M. L., Zaric, G. S., Freiesleben, J., Edwards, F. L., \& Bravata, D. M. (2008). An ounce of prevention is worth a pound of cure: Improving communication to reduce mortality during bioterrorism responses. American Journal of Disaster Medicine, 3(2), 65-78.

Bravata, D. M., Zaric, G. S., Holty, J. C., Brandeau, M. L., Wilhelm, E. R., Mcdonald, K. M., \& Owens, D. K. (2006). Reducing mortality from anthrax bioterrorism: Strategies for stockpiling and dispensing medical and pharmaceutical supplies. Biosecurity and Bioterrorism: Biodefense Strategy, Practice, and Science, 4(3), 244-262. https://doi.org/10.1089/bsp.2006.4.244.

Büyüktahtakın, E., Des-Bordes, E., \& Kıbış, E. Y. (2018). A new epidemics-logistics model: Insights into controlling the Ebola virus disease in West Africa. European Journal of Operational Research, 265, 1046-1063. https://doi.org/10.1016/j.ejor.2017.08.037.

Chinazzi, M., Davis, J. T., Ajelli, M., Gioannini, C., Litvinova, M., Merler, S., et al. (2020). The effect of travel restrictions on the spread of the 2019 novel coronavirus (COVID-19) outbreak. Science, in press, 368(6489), 395-400.

Cinti, S., Chenoweth, C., \& Monto, A. S. (2005). Preparing for pandemic influenza: should hospitals stockpile Oseltamivir? Infection Control and Hospital Epidemiology, 26(11), 852-854.

Collin, N., \& de Radiguès, X. (2009). Vaccine production capacity for seasonal and pandemic (H1N1) 2009 influenza. Vaccine, 27(38), 5184-5186. https://doi.org/10.1016/j.vaccine.2009.06.034.

Conn, R., Welch, F. J., \& Popovich, M. L. (2008). Management of vaccine inventories as a critical health resource: Lessons learned from Louisiana's 2007 mass-immunization exercise. IEEE Engineering in Medicine and Biology Magazine, 27(6), 61-65. https://doi.org/10.1109/MEMB.2008.929884.

Craft, D. L., Wein, L. M., \& Wilkins, A. H. (2005). Analyzing bioterror response logistics: The case of anthrax. Management Science, 51(5), 679-694. https://doi.org/10.1287/mnsc.1040.0348.

CSSE. (2020). Coronavirus (COVID-19) global cases. Center for systems science and engineering (CSSE), Johns Hopkins University (JHU). http://www.arcgis.com/apps/opsdashboard/index.html\#/ bda7594740fd40299423467b48e9ecf6. Accessed 31 May 2020.

Dato, V., Wagner, M. M., \& Fapohunda, A. (2004). How outbreaks of infectious disease are detected: A review of surveillance systems and outbreaks. Public Health Reports, 119(5), 464-471. https://doi. org/10.1016/j.phr.2004.07.003.

DeLaurentis, P. C., Adida, E., \& Lawley, M. (2008). A game theoretical approach for hospital stockpile in preparation for pandemics. In: Proceedings of the industrial engineering research conference (pp. 1772-1777).

DeLaurentis, P. C., Adida, E., \& Lawley, M. (2009). Hospital stockpiling for influenza pandemics with pre-determined response levels. In: Proceedings of the IEEE/INFORMS international conference on service operations, logistics and informatics (pp. 37-42). Chicago.

Dhankhar, P., Dasbach, E. J., \& Elbasha, E. H. (2009). Economics of stockpiling for an influenza pandemic. The Lancet Infectious Diseases. https://doi.org/10.1016/S1473-3099(09)70183-5.

Dhankhar, P., Grabenstein, J. D., O’Brien, M. A., \& Dasbach, E. J. (2010). Cost-effectiveness of stockpiling 23-valent pneumococcal polysaccharide vaccine to prevent secondary pneumococcal infections among a high-risk population in the United States during an influenza pandemic. Clinical Therapeutics, 32(8), 1501-1516. https://doi.org/10.1016/j.clinthera.2010.07.019.

Economic_Times (2020a). India Lockdown news: India to be under complete lockdown for 21 days starting midnight: Narendra Modi. https://economictimes.indiatimes.com/news/politics-and-natio n/india-will-be-under-complete-lockdown-starting-midnight-narendra-modi/articleshow/74796908. cms?from=mdr. Accessed 20 April 2020.

Economic_Times (2020b). Lockdown extended in India: PM Modi extends nationwide lockdown till May 3. https://economictimes.indiatimes.com/news/politics-and-nation/pm-modi-extends-nationallockdown-till-may-3/videoshow/75134788.cms?from=mdr. Accessed 20 April 2020.

Gautam, S., \& Hens, L. (2020). COVID-19: impact by and on the environment, health and economy. Environment, Development and Sustainability, 22(6), 4953-4954. https://doi.org/10.1007/s1066 8-020-00818-7.

Giovachino, M., Calhoun, T., Carey, N., Coleman, B., Gonzalez, G., Hardeman, B., \& McCue, B. (2005). Optimizing a District of Columbia strategic national stockpile dispensing center. Journal of Public Health Management and Practice, 11(4), 282-290. https://doi.org/10.1097/00124784-20050 7000-00004.

Hadler, J. L. (2005). Public health strategies for distribution of influenza vaccine during an influenza pandemic. Yale Journal of Biology and Medicine, 78(5), 277-286. 
Harrington, J. E., \& Hsu, E. B. (2010). Stockpiling anti-viral drugs for a pandemic: The role of manufacturer reserve programs. Journal of Health Economics, 29(3), 438-444. https://doi.org/10.1016/j.jheal eco.2010.02.004.

Hashikura, M., \& Kizu, J. (2009). Stockpile of personal protective equipment in hospital settings: Preparedness for influenza pandemics. American Journal of Infection Control, 37(9), 703-707. https://doi. org/10.1016/j.ajic.2009.05.002.

Herrmann, J. W., Lu, S., \& Schalliol, K. (2009). Delivery volume improvement for planning medication distribution. In: Proceedings of the international conference on systems, man and cybernetics (pp. 3505-3509). IEEE. https://doi.org/10.1109/ICSMC.2009.5346773.

Hessel, L. \& EVM-Group. (2009). Pandemic influenza vaccines: Meeting the supply, distribution and deployment challenges. Influenza and other Respiratory Viruses, 3(4), 165-170. https://doi.org/10.111 1/j.1750-2659.2009.00085.x.

Hu, J., \& Zhao, L. (2011). Emergency logistics strategy in response to anthrax attacks based on system dynamics. International Journal of Mathematics in Operational Research, 3(5), 490-509. https://doi. org/10.1504/IJMOR.2011.042440.

Hu, J., \& Zhao, L. (2012). Emergency logistics network based on integrated supply chain response to public health emergency. ICIC Express Letters, 6(1), 113-118.

Huang, R., Kim, S., \& Menezes, M. B. C. (2010). Facility location for large-scale emergencies. Annals of Operations Research, 181(1), 271-286. https://doi.org/10.1007/s10479-010-0736-8.

Hui, Q. (2010). Optimal control of bio-attack induced infectious disease dynamics: The case of anthrax. In Proceedings of the 6th International Conference on Automation Science and Engineering (pp. 911916). Canada: IEEE. https://doi.org/10.1109/COASE.2010.5584620

Hupert, N., Cuomo, J., Callahan, M. A., Mushlin, A. I. (2004). Community-based mass prophylaxis: a planning guide for public health preparedness. Bioterrorism and Other Public Health Emergencies Tools and Models for Planning and Preparedness Community-Based. http://archive.ahrq.gov/downloads/pub/ biotertools/cbmprophyl.pdf

Hupert, N., Mushlin, A. I., \& Callahan, M. A. (2002). Modeling the public health response to bioterrorism: Using discrete event simulation to design antibiotic distribution centers. Medical Decision Making, 22(Suppl), S17-S25. https://doi.org/10.1177/027298902237709.

Illahi, U., \& Mir, M. S. (2020a). Development of indices for sustainability of transportation systems: A review of state-of-the-art. Ecological Indicators, 118(June), 1-18. https://doi.org/10.1016/j.ecoli nd.2020.106760.

Illahi, U., \& Mir, M. S. (2020b). Sustainable Transportation Attainment Index: Multivariate analysis of indicators with an application to selected states and National Capital Territory (NCT) of India. Environment, Development and Sustainability, In press. https://doi.org/10.1007/s10668-020-00734-w.

Jennings, L. C., Monto, A. S., Chan, P. K., Szucs, T. D., \& Nicholson, K. G. (2008). Stockpiling prepandemic influenza vaccines: A new cornerstone of pandemic preparedness plans. The Lancet Infectious Diseases, 8(10), 650-658. https://doi.org/10.1016/S1473-3099(08)70232-9.

Jia, H., Ordóñez, F., \& Dessouky, M. (2007a). A modeling framework for facility location of medical services for large scale emergencies. IIE Transactions, 39(1), 41-55.

Jia, H., Ordóñez, F., \& Dessouky, M. M. (2007b). Solution approaches for facility location of medical supplies for large-scale emergencies. Computers and Industrial Engineering, 52(2), 257-276. https://doi. org/10.1016/j.cie.2006.12.007.

Kaplan, E. H., Craft, D. L., \& Wein, L. M. (2003). Analyzing bioterror response logistics: The case of smallpox. Mathematical Biosciences, 185(1), 33-72. https://doi.org/10.1016/S0025-5564(03)00090-7.

Kargar, S., Pourmehdi, M., \& Paydar, M. M. (2020). Reverse logistics network design for medical waste management in the epidemic outbreak of the novel coronavirus (COVID-19). Science of the Total Environment, 746, 141183. https://doi.org/10.1016/j.scitotenv.2020.141183.

Ke, Y., \& Zhao, L. (2008). Optimization of emergency logistics delivery model based on anti-bioterrorism. In Proceedings of the international conference on industrial engineering and engineering management (pp. 2077-2081). IEEE. https://doi.org/10.1109/IEEM.2008.4738237.

Krause, G., Altmann, D., Faensen, D., Porten, K., Benzler, J., Pfoch, T., et al. (2007). SurvNet electronic surveillance system for infectious disease outbreaks. Germany. Emerging Infectious Diseases, 13(10), 1548-1555. https://doi.org/10.3201/eid1310.070253.

Lee, E. K., Maheshwary, S., Mason, J., \& Glisson, W. (2006). Decision support system for mass dispensing of medications for infectious disease outbreaks and bioterrorist attacks. Annals of Operations Research, 148(1), 25-53. https://doi.org/10.1007/s10479-006-0087-7.

Lee, E. K., Chen, C.-H., Pietz, F., \& Benecke, B. (2009a). Modeling and optimizing the public-health infrastructure for emergency response. INFORMS Journal on Applied Analytics, 39(5), 476-490. https:// doi.org/10.1287/inte.1090.0463. 
Lee, E. K., Smalley, H. K., Zhang, Y., Pietz, F., \& Benecke, B. (2009b). Facility location and multi-modality mass dispensing strategies and emergency response for biodefence and infectious disease outbreaks. International Journal of Risk Assessment and Management, 12(2-4), 311-351. https://doi.org/10.1504/ ijram.2009.025925.

Lee, V. J., Kai, H. P., Chen, M. I., Chow, A., Ma, S., Goh, K. T., \& Leo, Y. S. (2006). Economics of neuraminidase inhibitor stockpiling for pandemic influenza. Singapore. Emerging Infectious Diseases, 12(1), 95-102. https://doi.org/10.3201/eid1201.050556.

Lee, Y. M. (2008). Analyzing dispensing plan for emergency medical supplies in the event of bioterrorism. In: Proceedings of the winter simulation conference (pp. 2600-2608).

Lee, Y. M., Ghosh S, Ettl, M. (2009). Simulating distribution of emergency relief supplies for disaster response operations. In: Proceedings of the winter simulation conference (pp. 2797-2808). IEEE. https ://doi.org/10.1109/WSC.2009.5429246.

Liberati, A., Altman, D., Tetzlaff, J., Mulrow, C., Gotzsche, P. C., Ioannidis, P. A., et al. (2009). The PRISMA statement for reporting systematic reviews and meta-analyses of studies that evaluate health care interventions: explanation and elaboration. PLoS Medicine, 6(7), 1000100.

Liu, M., Xu, X., Cao, J., \& Zhang, D. (2020). Integrated planning for public health emergencies: A modified model for controlling H1N1 pandemic. Journal of the Operational Research Society, 71(5), 748-761. https://doi.org/10.1080/01605682.2019.1582589.

Liu, M., \& Zhao, L. (2009). Optimization of the emergency materials distribution network with time windows in anti-bioterrorism system. International Journal of Innovative Computing, Information and Control, 5(11A), 3615-3624.

Liu, M., \& Zhao, L. (2012). An integrated and dynamic optimisation model for the multi-level emergency logistics network in anti-bioterrorism system. International Journal of Systems Science, 43(8), 14641478. https://doi.org/10.1080/00207721.2010.547629.

Liu, M., Zhao, L., \& Sebastian, H.-J. (2011). Mixed-collaborative distribution mode for emergency resources in an anti-bioterrorism system. International Journal of Mathematics in Operational Research, 3(2), 148-169. https://doi.org/10.1504/IJMOR.2011.038908.

Liu, Y. (2007). Mathematical models of vaccine inventory design for a breakout of epidemic disease. In: Proceedings in Applied Mathematics and Mechanics (Vol. 7, pp. 2150013-2150014). https://doi. org/10.1002/pamm.2007

Lombardo, J., Burkom, H., Elbert, E., Magruder, S., Lewis, S. H., Loschen, W., et al. (2003). A systems overview of the electronic surveillance system for the early notification of community-based epidemics (ESSENCE II). Journal of Urban Health, 80(2), 32-42. https://doi.org/10.1007/pl00022313.

Lugnér, A. K., \& Postma, M. J. (2009). Investment decisions in influenza pandemic contingency planning: Cost-effectiveness of stockpiling antiviral drugs. European Journal of Public Health, 19(5), 1-5. https ://doi.org/10.1093/eurpub/ckp119.

Manley, D. K., \& Bravata, D. M. (2009). A decision framework for coordinating bioterrorism planning: Lessons from the BioNet program. American Journal of Disaster Medicine, 4(1), 49-57.

Miller, G., Randolph, S., \& Patterson, J. E. (2006). Responding to bioterrorist smallpox in San Antonio. Interfaces, 36(6), 580-590. https://doi.org/10.1287/inte.1060.0228.

Moore, P. S., Toole, M. J., Nieburg, P., Waldman, R. J., \& Broome, C. V. (1990). Surveillance and control of meningococcal meningitis epidemics in refugee populations. Bulletin of the World Health Organization, 68(5), 587-596.

Murali, P., Ordóñez, F., \& Dessouky, M. M. (2012). Facility location under demand uncertainty: Response to a large-scale bio-terror attack. Socio-Economic Planning Sciences, 46(1), 78-87. https://doi. org/10.1016/j.seps.2011.09.001.

Patvivatsiri, L., Montes, E. J., and Xi, O. (2007). Modeling bioterrorism preparedness with simulation in rural healthcare system. In: Proceedings of the Winter Simulation Conference (pp. 1155-1160). https ://doi.org/10.1109/WSC.2007.4419716

Porco, T. C., Holbrook, K., Fernyak, S. E., Portnoy, D., Reiter, R., \& Aragón, T. J. (2004). Logistics of community smallpox control through contact tracing and ring vaccination: A stochastic network model. BMC Public Health, 4(34), 1-20. https://doi.org/10.1186/1471-2458-4-34.

Porter, R. M., Goldin, S., Lafond, K. E., Hedman, L., Ungkuldee, M., Kurzum, J., et al. (2020). Does having a seasonal influenza program facilitate pandemic preparedness? An analysis of vaccine deployment during the 2009 pandemic. Vaccine, 38(5), 1152-1159. https://doi.org/10.1016/j.vaccine.2019.11.025.

Pouraliakbarimamaghani, M., Mohammadi, M., \& Mirzazadeh, A. (2017). A Multi-objective Location-allocation model in mass casualty events response. Journal of Modelling in Management, 13(1), 236-274.

Radonovich, L. J., Magalian P. D., Hollingsworth, M. K., \& Baracco, G. (2009). Stockpiling supplies for the next influenza pandemic. Emerging Infectious Diseases (Vol. 15). http://www.embase.com/searc $\mathrm{h} /$ results? subaction=viewrecordandfrom=exportandid=L354750596\%5Cnhttp://www.cdc.gov/eid/ 
content/15/6/e1.htm\%5Cnhttps://doi.org/10.3201/eid1506.081196\%5Cnhttp://sfx.metabib.ch/sfx_ locater?sid=EMBASEandissn=10806040andid=doi:10.3201\%2Fei.

Rebmann, T., Carrico, R., \& English, J. F. (2007). Hospital infectious disease emergency preparedness: A survey of infection control professionals. American Journal of Infection Control, 35(1), 25-32. https://doi.org/10.1016/j.ajic.2006.07.002.

Rebmann, T., Citarella, B., Alexander, S., Russell, B., \& Volkman, J. C. (2011). Personal protective equipment use and allocation in home health during disasters. American Journal of Infection Control, 39(10), 823-831. https://doi.org/10.1016/j.ajic.2011.01.014.

Richter, A., \& Khan, S. (2009). Pilot model: Judging alternate modes of dispensing prophylaxis in Los Angeles County. Interfaces, 39(3), 228-240. https://doi.org/10.1287/inte.1080.0427.

Rottkemper, B., Fischer, K., \& Blecken, A. (2012). A transshipment model for distribution and inventory relocation under uncertainty in humanitarian operations. Socio-Economic Planning Sciences, 46(1), 98-109. https://doi.org/10.1016/j.seps.2011.09.003.

Rottkemper, B., Fischer, K., Blecken, A., \& Danne, C. (2011). Inventory relocation for overlapping disaster settings in humanitarian operations. OR Spectrum, 33(3), 721-749. https://doi.org/10.1007/ s00291-011-0260-5.

Shen, Z., Dessouky, M. M., \& Ordóñez, F. (2009). A two-stage vehicle routing model for large-scale bioterrorism emergencies. Networks, 54(4), 255-269. https://doi.org/10.5555/1670696.1670705.

Siddiqui, M. R., \& Edmunds, W. J. (2008). Cost-effectiveness of antiviral stockpiling and near-patient testing for potential influenza pandemic. Emerging Infectious Diseases, 14(2), 267-274. https://doi. org/10.3201/eid1402.070478.

Silal, S. P. (2020). Operational research: A multidisciplinary approach for the management of infectious disease in a global context. European Journal of Operational Research, In press. https://doi. org/10.1016/j.ejor.2020.07.037.

Tebbens, R. J. D., Pallansch, M. A., Alexander, J. P., \& Thompson, K. M. (2010). Optimal vaccine stockpile design for an eradicated disease: Application to polio. Vaccine, 28(26), 4312-4327. https://doi. org/10.1016/j.vaccine.2010.04.001.

Tumpey, T. M., Basler, C. F., Aguilar, P. V., Zeng, H., Solorzano, A., Swayne, D. E., et al. (2005). Characterization of the reconstructed 1918 Spanish influenza pandemic virus. Science, 310(October), $77-80$.

Wang, H., Wang, X., \& Zeng, A. Z. (2009). Optimal material distribution decisions based on epidemic diffusion rule and stochastic latent period for emergency rescue. International Journal of Mathematics in Operational Research, 1(1/2), 76-96. https://doi.org/10.1504/IJMOR.2009.022876.

Whitworth, M. H. (2006). Designing the response to an anthrax attack. Interfaces, 36(6), 562-568. https ://doi.org/10.1287/inte.1060.0241.

WHO (2005). Communicable disease control in emergencies: a field manual. World Health Organization.

WHO (2010). Pandemic (H1N1) 2009 update 102. World Health Organization (WHO). https://www. who.int/csr/don/2010_05_28/en/.

WHO (2012). WHO Activity Report. World Health Organization.

WHO (2020a). Emergencies preparedness, response: Novel Coronavirus-China. World Health Organization (WHO). https://www.who.int/csr/don/12-january-2020-novel-coronavirus-china/en/. Accessed 10 April 2020.

WHO (2020b). WHO announces COVID-19 outbreak a pandemic. World Health Organization (WHO). http://www.euro.who.int/en/health-topics/health-emergencies/coronavirus-covid-19/news/ news/2020/3/who-announces-covid-19-outbreak-a-pandemic. Accessed 16 April 2020.

WHO (2020c). Coronavirus disease 2019 (COVID-19) Situation Report-86. World Health Organization.

Xu, J., Zhao, L., \& Wang, H. (2009). Collaborative research between epidemic diffusion network and emergency rescue network in anti-bioterrorism system. In: Proceedings of the international joint conference on computational sciences and optimization (Vol. 2, pp. 630-634). IEEE. https://doi. org/10.1109/CSO.2009.401.

Yıldızbaş1, A., Öztürk, C., Efendioğlu, D., \& Bulkan, S. (2020). Assessing the social sustainable supply chain indicators using an integrated fuzzy multi-criteria decision-making methods: a case study of Turkey. Environment, Development and Sustainability, In press. https://doi.org/10.1007/s1066 8-020-00774-2.

Zaric, G. S., Bravata, D. M., Holty, J.-E.C., McDonald, K. M., Owens, D. K., \& Brandeau, M. L. (2008). Modeling the logistics of response to anthrax bioterrorism. Medical Decision Making, 28(3), 332350. https://doi.org/10.1177/0272989X07312721.

Zerang, E. S., Taleizadeh, A. A., \& Razmi, J. (2018). Analytical comparisons in a three-echelon closed-loop supply chain with price and marketing effort-dependent demand: game theory approaches. Environment, Development and Sustainability, 20, 451-478. https://doi.org/10.1007/s10668-016-9893-5. 
Zhao L., \& Sun, L. (2008). Emergency service modes of supply chains with replenishment sources. In: Proceedings of the 5 th international conference on service systems and service management - exploring service dynamics with science and innovative technology. Melbourne: IEEE. https://doi.org/10.1109/ ICSSSM.2008.4598534.

Zhao, W., \& Han, R. (2010). Optimal model of emergency relief supplies distribution in anti-bioterrorism system. In: Proceedings of the international conference on logistics systems and intelligent management (pp. 1618-1622). IEEE. https://doi.org/10.1109/ICLSIM.2010.5461244.

Zhu L., \& Cao, J. (2010). A network equilibrium model for emergency logistics response under disaster spreading. In: Proceedings of international conference on logistics engineering and intelligent transportation systems (pp. 1-4). IEEE. https://doi.org/10.1109/LEITS.2010.5664931.

Publisher's Note Springer Nature remains neutral with regard to jurisdictional claims in published maps and institutional affiliations. 